\title{
Erosive cola-based drinks affect the bonding to enamel surface: an in vitro study
}

Leslie Caroll CASAS-APAYCO' ${ }^{1}$, Vanessa Manzini DREIBI ${ }^{2}$, Ana Carolina HIPÓLITO ${ }^{3}$, Márcia Sirlene Zardin GRAEFF ${ }^{4}$, Daniela RIOS ${ }^{5}$, Ana Carolina MAGALHÃES ${ }^{6}$, Marília Afonso Rabelo BUZALAF ${ }^{6}$, Linda WANG ${ }^{7}$

\author{
1- Department of Operative Dentistry, Endodontics and Dental Materials, Bauru School of Dentistry, University of São Paulo, Bauru, SP, Brazil; School of \\ Dentistry, Universidad Peruana de Ciencias Aplicadas, Lima, Peru. \\ 2- Private practice, Bauru, SP, Brazil. \\ 3- Department of Dental Materials and Prosthodontics, Araçatuba Dental School, Univ. Estadual Paulista (UNESP), Araçatuba, SP, Brazil. \\ 4- Integrated Research Center, Bauru School of Dentistry, University of São Paulo, Bauru, SP, Brazil. \\ 5- Department of Pediatric Dentistry, Orthodontics and Community Health, Bauru School of Dentistry, University of São Paulo, Bauru, SP, Brazil. \\ 6- Department of Biological Sciences, Bauru School of Dentistry, University of São Paulo, Bauru, SP, Brazil. \\ 7- Department of Operative Dentistry, Endodontics and Dental Materials, Bauru School of Dentistry, University of São Paulo, Bauru, SP, Brazil.
}

Corresponding address: Linda Wang - Faculdade de Odontologia de Bauru - Al. Dr. Octávio Pinheiro Brisolla, n. 9-75 - Vila Universitária - Bauru - SP - Brasil - 17012-101 - Phone: +55-14-3235-8323/8480 - fax:+55-14-3235-8323 - e-mail: wang.linda@usp.br

Submitted: September 14, 2013 - Modification: December 26, 2013 - Accepted: January 29, 2014

\section{ABSTRACT}

\begin{abstract}
bjective: This study aimed to assess the impact of in vitro erosion provoked by different cola-based drinks (Coke types), associated or not with toothbrushing, to bonding to enamel. Material and Methods: Forty-six bovine enamel specimens were prepared and randomly assigned into seven groups $(\mathrm{N}=8)$ : C- Control (neither eroded nor abraded), ERO-RC: 3x/1-min immersion in Regular Coke (RC), ERO-LC: 3x/1-min immersion in Light Coke (LC), ERO-ZC: $3 x / 1$-min immersion in Zero Coke (ZC) and three other eroded groups, subsequently abraded for 1-min toothbrushing (EROAB-RC, EROAB-LC and EROAB-ZC, respectively). After challenges, they were stored overnight in artificial saliva for a total of $24 \mathrm{~h}$ and restored with Adper Single Bond 2/Filtek Z350. Build-up coronal surfaces were cut in $1 \mathrm{~mm}^{2}$-specimens and subjected to a microtensile test. Data were statistically analyzed by two-way ANOVA/Bonferroni tests $(\alpha=0.05)$. Failure modes were assessed by optical microscopy (X40). The interface of the restorations were observed using Confocal Laser Scanning Microscopy (CLSM). Results: All tested cola-based drinks significantly reduced the bond strength, which was also observed in the analyses of interfaces. Toothbrushing did not have any impact on the bond strength. CLSM showed that except for Zero Coke, all eroded specimens resulted in irregular hybrid layer formation. Conclusions: All colabased drinks reduced the bond strength. Different patterns of hybrid layers were obtained revealing their impact, except for ZC.
\end{abstract}

Keywords: Tooth abrasion. Bonding agent. Enamel. Erosion. Soft drinks.

\section{INTRODUCTION}

Dental erosion is a common problem in modern societies, owing to the increased consumption of acidic drinks, such as soft drinks, sport drinks, fruit juices, and fruit teas, which in turn have a high potential to provoke dental demineralization ${ }^{3,8,12}$. Up to now, most clinical reports are generally related with a later intervention, in which the non-carious lesions as erosion, especially in cervical area of the tooth, present dentin exposure, hypersensitivity, and more complex restorative needs $6,15,17,23,24$.
Erosion is a superficial demineralization process that softens the surface with subsequent wear until reaching dentin ${ }^{3,9,17,23}$. Substrate compromising depends on the etiologic agent and intensity of challenge ${ }^{3,9,14,17,23}$. As erosion is normally associated with other non-carious lesions such as abrasion, its sole cause in dental substrates is difficult to establish, since erosion consists of lesions from multiple etiologies, which may result in the need for a restorative procedure ${ }^{3,6,12,15,24}$.

Although enamel is considered a simple and safe substrate for bonding ${ }^{13,14}$, there is lack of 
research regarding this property to eroded tooth. As erosion provokes alterations on this substrate, details of these modifications on bonding turn the investigations necessary. A few reports ${ }^{17}$ presented an early intervention, restoring enamel. As these substrates will be subsequently restored, mostly using adhesive materials, this interaction needs to be clarified.

Thus, this investigation aimed to test the impact of different Coke drinks on adhesion to previouslyeroded enamel surfaces. The null hypotheses are that (1) different Coke drinks do not provoke differences on adhesion to enamel, and (2) their association with toothbrushing does not have any impact on the adhesion process either.

\section{MATERIAL AND METHODS}

\section{Experimental design}

This experiment was conducted considering two factors: Erosive challenges by soft drinks (in four levels: none/artificial saliva, RC, LC, and ZC) and toothbrushing effect (in two levels: none or following erosive challenge). The response variable was based on bond strength.

\section{Preparation of the specimens}

Fifty-six enamel specimens $(4 \times 4 \times 2 \mathrm{~mm})$ were obtained from freshly-extracted bovine incisors, which were previously stored in $0.1 \%$ thymol solution at room temperature. One specimen was cut from each crown using an Isomet Low-Speed Saw cutting machine (Buehler, Lake Bluff, IL, USA) and two diamond disks (Extec Corp., Enfield, CT, USA), which were separated by a $4 \mathrm{~mm}$ thickness spacer. The enamel surface was flat with watercooled carborundum discs (\#320, 600, and 1200 of $\mathrm{Al}_{2} \mathrm{O}_{3}$ papers; Buehler, Lake Bluff, IL, USA), resulting in enamel removal of about $100 \mu \mathrm{m}$ depth. This series was completed with polishing using felt paper made wet by diamond spray ( $1 \mu \mathrm{m}$; Buehler, Lake Bluff, IL, USA). In order to standardize the enamel surfaces, they were selected using a micro-hardness test by performing five indentations in different regions of the block (Knoop diamond, $25 \mathrm{~g}, 5 \mathrm{~s}$, HMV-2000; Shimadzu Corporation, Tokyo, Japan). Enamel blocks with a Knoop hardness number ranging from 320 to $385 \mathrm{KHN}$ were selected.

\section{Erosive protocols}

Composition and chemical characteristics of each immersion media are presented in Figure 1. Selected specimens were randomly assigned into seven groups $(n=8)$ according to immersion media and toothbrushing association or not as presented in Figure 2.

\section{Restorative procedures}

After the erosive/abrasive challenge, each specimen was carefully cleaned under a deionized water flow for $2 \mathrm{~min}$. Acid etching was performed using 37\% phosphoric acid (Dentsply Ind. Com. Ltda, Petrópolis, RJ, Brazil) for $15 \mathrm{~s}$, which was washed out for a $30 \mathrm{~s}$. A gentle air-stream was used to promote water evaporation, which was completed with absorbent paper. Two thin coats of an etch-and-rinse dentin bonding system (Adper Single Bond 2- 3M ESPE, St. Paul, MN, USA) were subsequently dispensed with a disposable microbrush and gently air-dried for 2-5 s to allow solvent evaporation and followed by light curing for $10 \mathrm{~s}$ with a $1,000 \mathrm{~mW} / \mathrm{cm}^{2}$ power density LED unit (Radi cal-SDI, Bayswater, Victoria, Australia). Thus, the enamel surface was restored with two layers of $2 \mathrm{~mm}$ thickness increments of a nano-filled $\mathrm{A} 2$ shade resin composite (Filtek Z350-3M ESPE, St. Paul, MN, USA) and light-activated for 20 s.

\section{Microtensile bond strength}

After $24 \mathrm{~h}$ of water immersion in $37^{\circ} \mathrm{C}$, each

\begin{tabular}{|c|c|}
\hline Immersion media & Composition* \\
\hline Artificial saliva & 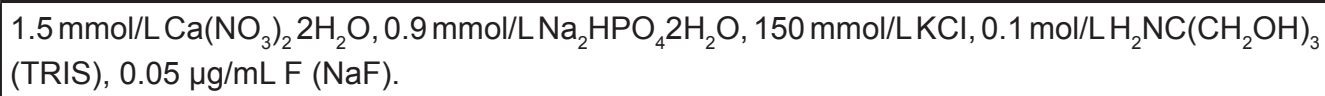 \\
\hline Regular Coke & $\begin{array}{l}\text { carbonated water, high fructose syrup, caramel color, phosphoric acid, natural flavors, caffeine } \\
\text { content: } 23 \mathrm{mg} / 8 \mathrm{fl} \mathrm{oz} \text {, very low sodium. } \mathrm{pH}=2.74 \text {; tritability=120 } \mathrm{mL}(0.1 \mathrm{~N} \mathrm{NaOH}) \text {. }\end{array}$ \\
\hline Light Coke & $\begin{array}{l}\text { Carbonated water, nutmeg extract, caramel color, } 24 \mathrm{mg} / 100 \mathrm{~mL} \text { aspartame, } 16 \mathrm{mg} / 100 \mathrm{~mL} \\
\text { potassium acesulfame, phosphoric acid, sodium benzoate, sodium citrate, natural flavors, } \\
\text { caffeine. } \mathrm{pH}=3.00 \text {; tritability }=12 \mathrm{~mL}(0 . \mathrm{N} \mathrm{NaOH}) \text {. }\end{array}$ \\
\hline Zero Coke & $\begin{array}{l}\text { carbonated water, caramel color, phosphoric acid, aspartame, potassium benzoate (to } \\
\text { protect taste), natural flavors, potassium citrate, acesulfame potassium, phenylketonurics, } \\
\text { phenylalanine, caffeine content: } 23 \mathrm{mg} / 8 \mathrm{fl} \mathrm{oz} \text {, very low sodium. } \mathrm{pH}=3.08 \text {; tritability }=91 \mathrm{~mL}(0.1 \\
\mathrm{N} \mathrm{NaOH}) \text {. }\end{array}$ \\
\hline
\end{tabular}

* Based on manufacturer's information, except for $\mathrm{pH}$ and tritability, which were assessed by the authors

Figure 1- Composition of artificial saliva and coke beverages 
restored enamel specimen was Iongitudinally sectioned in directions across the bonded interface using an Isomet 1000 digital saw (Buehler Ltd., Lake Bluff, IL, USA) to obtain specimens with an interface area of approximately $1 \mathrm{~mm}^{2}$. An average of 6-8 beams per specimen was obtained. Each beam was attached to a modified Bencor Multi-T testing apparatus (Danville Engineering Co., Danville, CA, USA) with a cyanoacrylate resin (Super Bonder Flex Gel-Loctite, Henckel Ltda, Itapevi, SP, Brazil) and submitted to test under tension in a universal testing machine (Emic, São José dos Pinhais, PR, Brazil) operating at a crosshead speed of $0.5 \mathrm{~mm} /$ min. After testing, the cross-sectional area at the site of fracture was measured with a digital caliper (Mitutoyo Digimatic Caliper Series/Code 500-144, Mitutoyo Sul Americana, RJ, Brazil) to calculate bond strength in mega Pascal ( $\mathrm{MPa}$ ).

\section{Statistical analysis}

Data analysis was accomplished by the Graph Pad/Prisma statistical package (GraphPad InStat for Windows version 4.0, San Diego, CA, USA). The assumptions of equality of variances and normal distribution of errors were checked for all the variables tested. Since the assumptions were satisfied, two-way analysis of variance (ANOVA) and Bonferroni post hoc tests were carried out for statistical comparisons and the significance was preset to $5 \%$.

\section{Stereomicroscopy analysis}

After bonding tests, each interface was analyzed with a stereomicroscopy 40x and was categorized according to failure as: adhesive failure (failure between the enamel and bonding layer), cohesive failure in enamel (when failure occurred predominantly in enamel) or in resin (when failure occurred predominantly in resin) or mixed failure (when two or more types were observed simultaneously).

\section{Confocal Laser Scanning Microscopy (CLSM)}

For each group, two additional specimens were prepared with half of the surface protected with nail varnish in order to maintain a control surface. After the challenges, nail varnish was removed with acetone and the specimens were restored in similar conditions as described above. However, Rhodamine B (Sigma-Aldrich Brasil, São Paulo, SP, Brazil) was added to Adper Single Bond 2 in 0.16 $\mathrm{mg} / \mathrm{mL}$ as a fluorescent ingredient to be detected in $\mathrm{CLSM}^{4}$. Following, the specimens were cut in the middle to obtain two halves containing control and exposed specimens to analyze the interfaces with the confocal microscope (Leica TCS SPE, Leica Microsystems CMS, Mannheim, Germany) using the microscope's software (Leica Application Suite Advanced Fluorescence, Leica Microsystems CMS, Mannheim, Germany). The quality of the interfaces was analyzed by examining both halves of each specimen with $40 x$ (each $1.0^{\circ}-1.0 \mathrm{~mm}, 1,024$ pixels and $0.976 \mu \mathrm{m}$ in resolution).

\section{RESULTS}

Bond strength means and standard deviations are summarized in Table 1 and Figure 3.

The factor erosion (type of coke drink) revealed statistical significance $(p<0.05)$. In contrast, no significance was attributed to abrasion performed by toothbrushing $(p>0.05)$.

\begin{tabular}{|c|c|c|}
\hline & No abrasion (ERO) & $\begin{array}{l}\text { Following abrasion by mechanical toothbrushing } \\
\qquad \text { (EROAB) }\end{array}$ \\
\hline Control & Artificial saliva immersion for $24 \mathrm{~h}$ & ----- \\
\hline ERO-RC & $\begin{array}{l}3 \mathrm{x} / 1 \text { min immersion in regular Coke. } \\
\text { Between the erosive challenges, the } \\
\text { specimens were exposed to artificial saliva } \\
\text { for a total of } 24 \mathrm{~h} \text {. }\end{array}$ & $\begin{array}{l}\text { 3x/1 min immersion in Regular Coke plus } 1 \text { min toothbrushing } \\
\text { abrasion (Oral B Cross Action Power, Oral B do Brasil Ltda, } \\
\text { Rio de Janeiro, RJ, Brazil) with one drop of previously-prepared } \\
\text { slurry ( } 3: 1 \mathrm{w} / \mathrm{w} \text { toothpaste - Oral B, Oral B do Brasil Ltda, Rio } \\
\text { de Janeiro, RJ, Brazil/deionized water). After each cycle, } \\
\text { specimens were immersed in artificial saliva for a total of } 24 \mathrm{~h} \text {. }\end{array}$ \\
\hline ERO-LC & $\begin{array}{l}3 \mathrm{x} / 1 \text { min immersion in Light Coke. Between } \\
\text { the erosive challenges, the specimens } \\
\text { were exposed to artificial saliva for a total } \\
\text { of } 24 \mathrm{~h} \text {. }\end{array}$ & $\begin{array}{l}3 \mathrm{x} / 1 \mathrm{~min} \text { immersion in Light Coke plus } 1 \mathrm{~min} \text { toothbrushing } \\
\text { abrasion as described above and immersion in artificial saliva } \\
\text { for a total of } 24 \mathrm{~h} \text {. }\end{array}$ \\
\hline ERO-ZC & $\begin{array}{l}3 \mathrm{x} / 1 \text { min immersion in Zero Coke. Between } \\
\text { the erosive challenges, the specimens } \\
\text { were exposed to artificial saliva for a total } \\
\text { of } 24 \mathrm{~h} \text {. }\end{array}$ & $\begin{array}{l}3 \mathrm{x} / 1 \mathrm{~min} \text { immersion in Zero Coke plus } 1 \mathrm{~min} \text { toothbrushing } \\
\text { abrasion as described above and immersion in artificial saliva } \\
\text { for a total of } 24 \mathrm{~h} \text {. }\end{array}$ \\
\hline
\end{tabular}

Figure 2- Groups tested according to erosive/abrasive challenges 
Table 1- Means and standard deviations (MPa) of eroded/abraded enamel specimens restored with resin composite

\begin{tabular}{ccccc}
\hline & Control & ERO-RC & ERO-LC & ERO-ZC \\
\hline NO & $23.92(3.68)^{\mathrm{Aa}}$ & $15.38(3.82)^{\mathrm{Ba}}$ & $14.18(2.87)^{\mathrm{Ba}}$ & $15.90(2.68)^{\mathrm{Ba}}$ \\
$\mathrm{AB}$ & & $14.71(1.98)^{\mathrm{Ba}}$ & $16.16(2.37)^{\mathrm{Ba}}$ & $12.53(3.93)^{\mathrm{Ba}}$ \\
\hline
\end{tabular}

$\mathrm{N}=8$

*Uppercase letters show significant differences among the erosive challenges for each abrasion condition (columns) $(p<0.05)$. Lower case letters show significant differences between the association with or without abrasive challenge for each erosive condition (rows)

ERO-RC=eroded with regular Coke; ERO-LC=eroded with Light Coke; ERO-ZC=eroded with Zero Coke; NO=not abraded and $A B=$ abraded

Table 2- Failure mode distribution according to challenge (\%)

\begin{tabular}{|c|c|c|c|c|}
\hline Challenge & Failure mode & & Percentage & \\
\hline \multirow[t]{5}{*}{ Control } & Mixed & & 34.62 & \\
\hline & Adhesive & & 46.15 & \\
\hline & Cohesive/Enamel & & 19.23 & \\
\hline & Cohesive/Resin & & 0.00 & \\
\hline & & $\mathrm{RC}$ & LC & ZC \\
\hline \multirow[t]{4}{*}{ ERO } & Mixed & 52.94 & 58.33 & 33.33 \\
\hline & Adhesive & 17.65 & 25.00 & 37.04 \\
\hline & Cohesive/Enamel & 29.41 & 16.67 & 25.93 \\
\hline & Cohesive/Resin & 0.00 & 0.00 & 3.70 \\
\hline \multirow[t]{4}{*}{ EROAB } & Mixed & 71.43 & 46.15 & 42.86 \\
\hline & Adhesive & 28.57 & 30.77 & 35.71 \\
\hline & Cohesive/Enamel & 0.00 & 23.08 & 21.43 \\
\hline & Cohesive/Resin & 0.00 & 0.00 & 0.00 \\
\hline
\end{tabular}

ERO-RC=eroded with regular Coke; ERO-LC=eroded with Light Coke; ERO-ZC=eroded with Zero Coke; NO=not abraded and $\mathrm{AB}=$ abraded; $\mathrm{RC}=$ regular Coke; $\mathrm{LC}=$ Light Coke; $\mathrm{ZC}=$ Zero Coke

The control group (neither eroded nor abraded) showed significantly greater bond strength compared to all other situations $(p<0.05)$. For the eroded groups, all coke drinks resulted in a

\section{Bond strength of eroded/abraded groups}

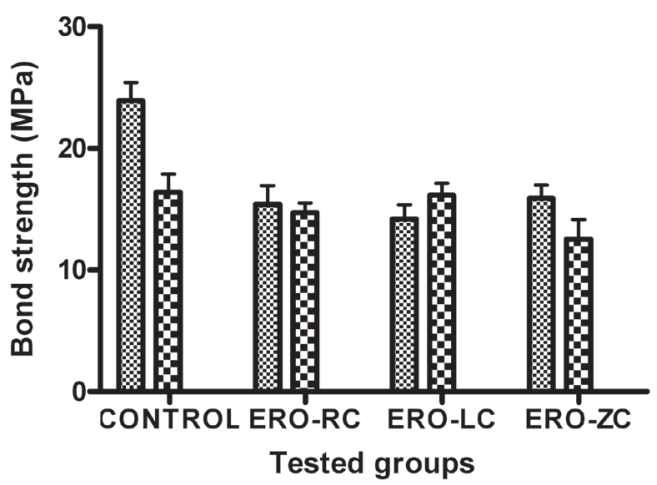

Figure 3- Bond strengths (MPa) for all tested conditions; comparing each eroded challenge in abraded and not abraded conditions significant decrease in bond strength compared to the control group $(p<0.05)$; however, no differences were found among the bonding to eroded groups previously treated with any coke drinks ( $p>0.05$ ). In the comparison of bond strength of specimens submitted to erosion to each coke drink to their respective association with abrasion, no differences were observed ( $p>0.05)$.

Description of distribution of the failure modes for each tested group is presented in Table 2. It could be observed that the sum of mixed and adhesive failures was evident in all conditions. Cohesive failure in resin was only present in groups eroded by ZC $(3.70 \%)$. Cohesive failure in enamel was also present for all conditions, except for RC associated with abrasion.

Under CLSM observation, a control pattern in specimens (not challenged) is illustrated in Figure 4, which showed a uniform and regular tag formation, with homogeneous thickness and regular extension into enamel. On the other hand, distinct 
performance was revealed comparatively regarding each coke drink that was used.

RC (ERO-RC and EROAB-RC specimens) caused superficial and heterogeneous tag formation (Figures 5a, b). It was observed that there was poor tag formation for the eroded specimens. However, for EROAB-RC specimens, even also poorly visible, tags were more regular than for ERO-RC specimens. A similar result was shown for ERO-LC, in which

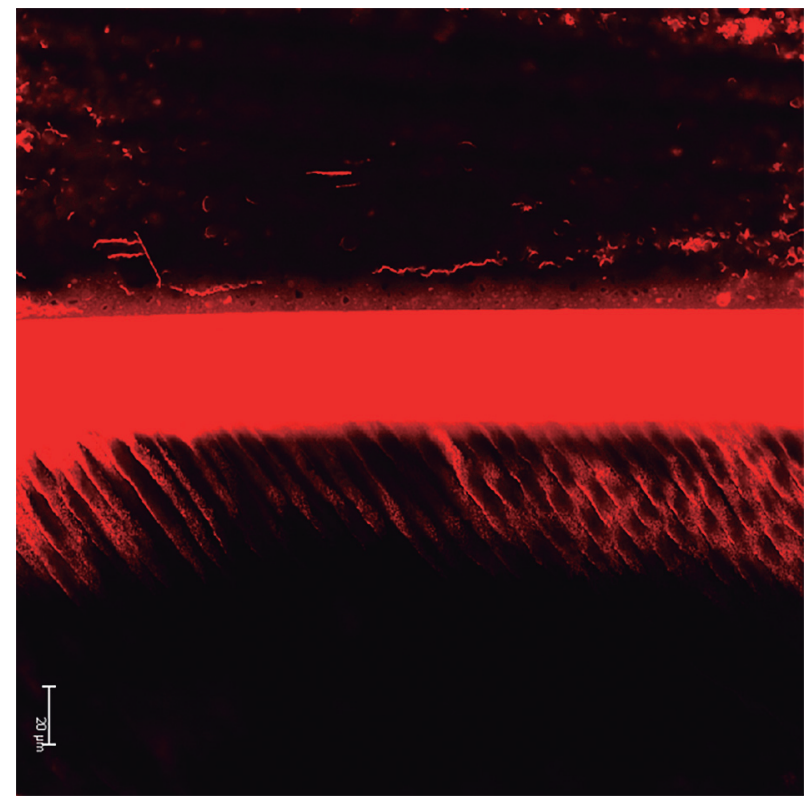

Figure 4- Interface aspect of bonding system to enamel surface (control). Tags are presented in homogeneous extent

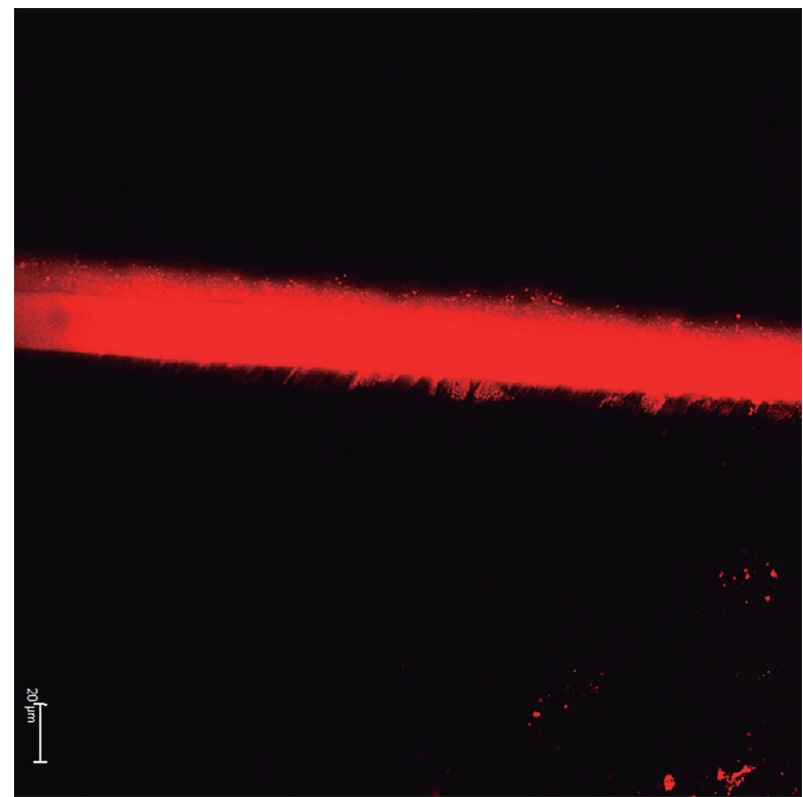

Figure 5a- Interface aspect of bonding system to enamel surface eroded by regular Coke (RC). Tags are not easily observed. Hybrid layer is based on superficial tags formation the adhesive impregnation was more superficial compared to control (Figures 6a, b). For EROAB-LC, the adhesive layer showed to be more regular than only eroded specimens.

Only ZC allowed similar tag formation compared to the control group, regardless of the abrasion. The interface characteristics of these groups (ERO-ZC and EROAB-ZC) can be observed in Figure 7a, b.

\section{DISCUSSION}

Poor evidence is reported on the adhesion to enamel previously eroded by different soft drinks. While enamel is a dental substrate that allows the formation of regular and strong adhesion ${ }^{13}$, changes in this substrate might affect the bond strength, failure mode, and the tag formation ${ }^{1}$.

Based on the results of this study, the first null hypothesis was rejected while the second null hypothesis was accepted. Data attested the potential of cola-based drinks, as Coke types, to reduce bond strength in enamel compared with the control condition. As Coke drinks are based on phosphoric acid content $(\mathrm{pH}$ 2.6-3.0), they showed to be potentially erosive, which was previously stated $5,8,9,19,20,25$. According to Figure 1, all tested drinks presented similar $\mathrm{pH}$. RC and LC present the same titratable acidity, which were higher than presented by ZC. Titratable acidity is related to the amount of base required to allow a solution with neutral $\mathrm{pH}$, which exhibits relevant influence on demineralization ${ }^{5,19,20,25}$. Thus, it can be expected that there will be higher compromising by RC and LC. By means of bond strength, this performance

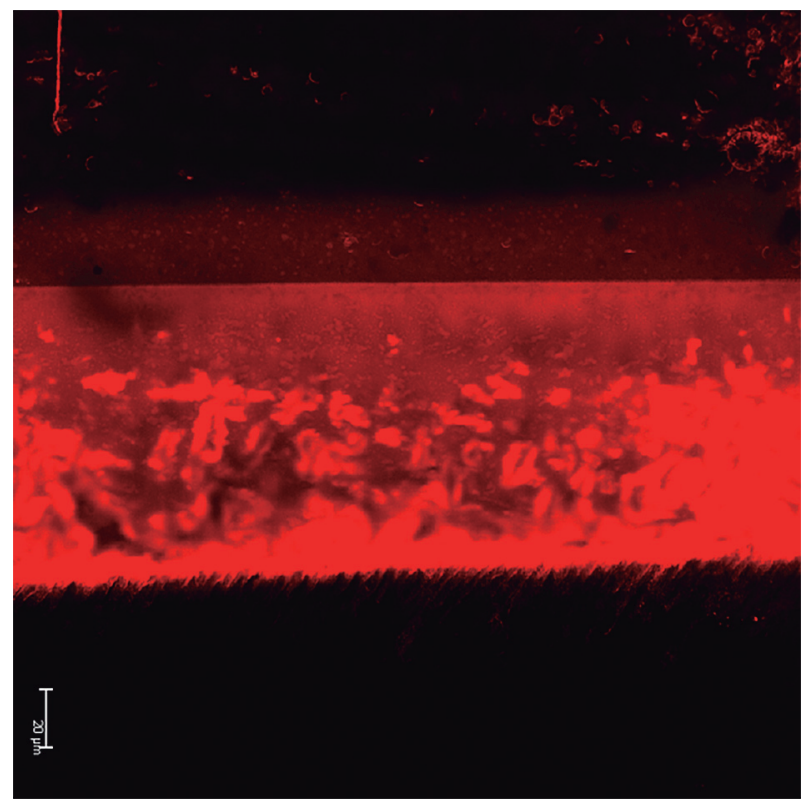

Figure 5b- Interface aspect of bonding system to enamel surface eroded by regular Coke (RC) followed by toothbrushing. Hybrid layer is irregular and superficial, but it is more evident than only eroded surface 


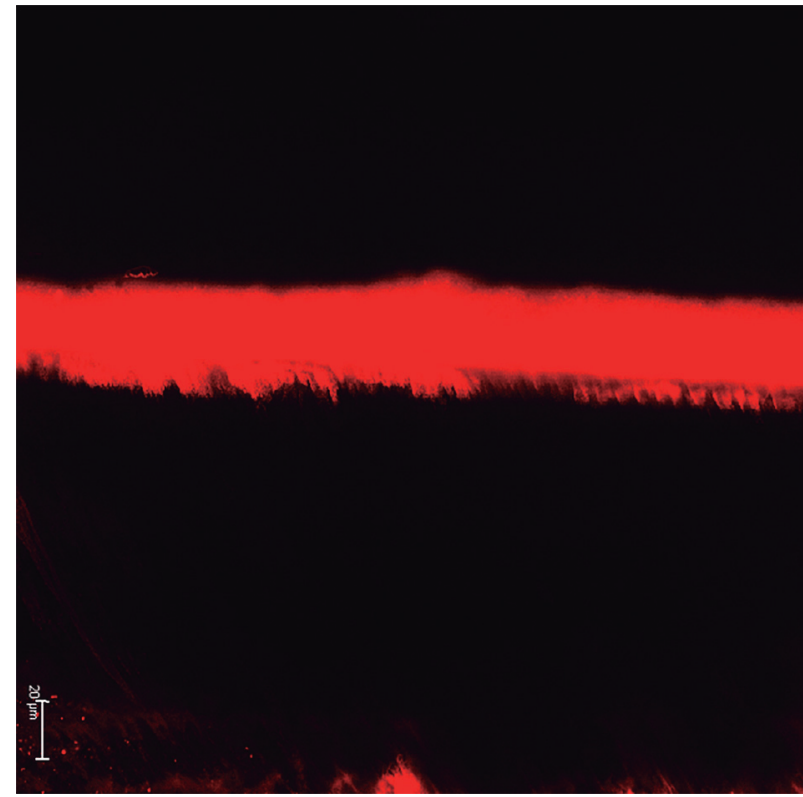

Figure 6a- Interface aspect of bonding system to enamel surface eroded by Light Coke (LC). Tags are thin and irregular

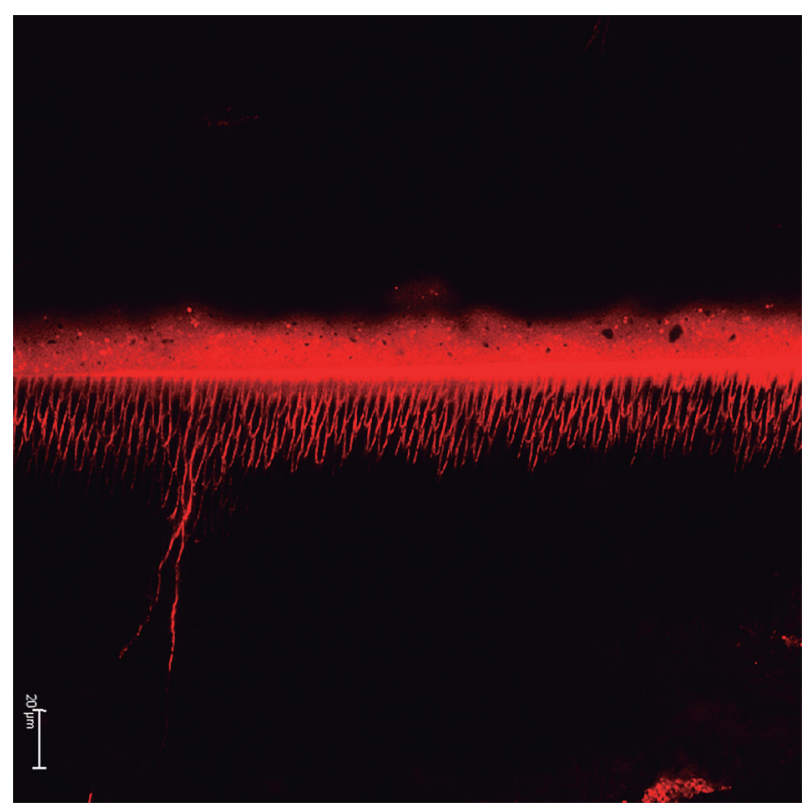

Figure 7a- Interface aspect of bonding system to enamel surface eroded by Zero Coke (ZC). Tags present homogeneous pattern

was not confirmed as all drinks negatively influenced adhesion with no difference among them. However, in light of the failure mode interpretation, we can observe a similar pattern of failure mode between RC and LC, with a predominant occurrence of mixed and adhesive failures, which differed from ZC (Table 2). A previous study ${ }^{19}$ suggested that LC was less erosive than RC. This less-erosive potential was attributed to the presence of the amino acid phenylalanine, which is provided by the

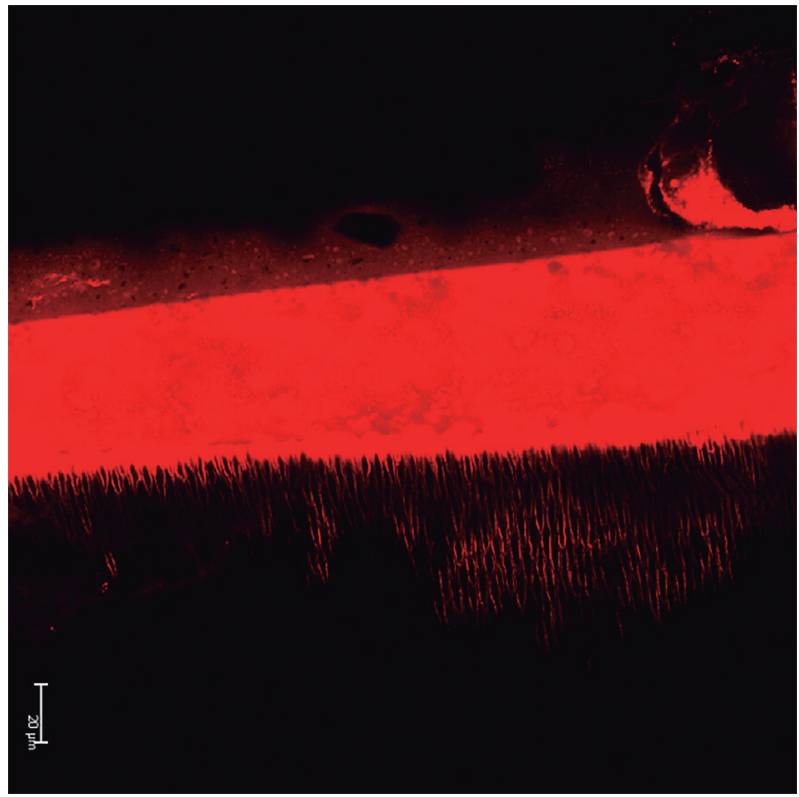

Figure 6b- Interface aspect of bonding system to enamel surface eroded by Light Coke (LC) followed by toothbrushing. Hybrid layer is also superficial, but much more regular than only eroded surface

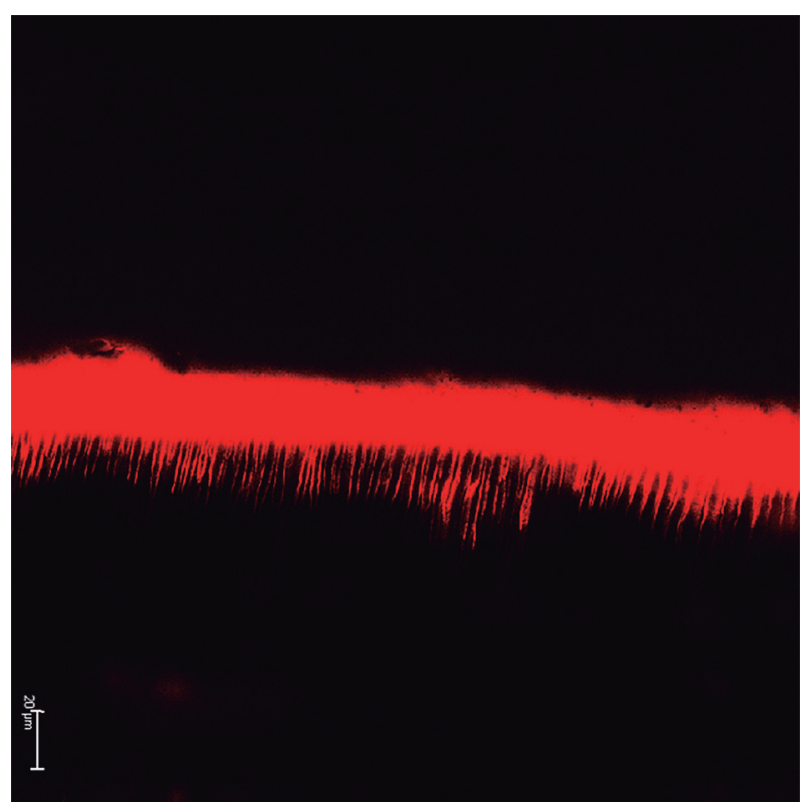

Figure $7 \mathbf{b}$ - Interface aspect of bonding system to enamel surface eroded by Zero Coke (ZC) followed by toothbrushing. Hybrid layer is not affected as in the control group

hydrolysis of aspartame in the presence of saliva. As the present study was conducted under the in vitro experimental model, there was no influence of saliva, which in turn may be responsible for the lack of differences between RC and LC.

The performance of $Z C$ reveals that it was the only group that presented cohesive failure in resin. Likely, this beverage might provoke irregularities of 
surface, which intensity was favorable to bond. A rougher surface is attributed to playing a relevant role in the adhesion mechanism, as it contributes to promoting more intense interlocking to enamel ${ }^{10}$.

Abrasion was the other factor considered in this investigation. Early stages of enamel dissolution are accompanied by a weakening of the surface. However, the fragile enamel surface can be lost if the erosive challenge continues ${ }^{9,11,18,21,22}$. This softened zone is also more susceptible to mechanical forces, such as abrasion ${ }^{9,11,18,21,22}$. Control group, associated with toothbrushing, presented no difference in relation to respective solely eroded group. When $\mathrm{RC}$ was associated with toothbrushing (EROAB$\mathrm{RC}$ ), cohesive failure in enamel was not evident, suggesting that the eroded surface was removed by abrasion. For LC and ZC, it might be prudent to speculate that the toothbrushing has a minor impact on the enamel loss, due to the low erosive demineralization provoked by these drinks ${ }^{20}$. Despite the fact that some studies have shown that toothbrushing seems to have some effects on acid-softened hard tissues ${ }^{18,22}$, the abrasion of the eroded enamel surface did not have a major impact on bond strength and failure mode in the present study.

CLSM images are in accordance with the speculated interpretation of overall results (Figures 4 to $7 b$ ). Except for ZC, all other eroded specimens presented an irregular hybrid layer formation. Both RC and LC reduced the tag formation. However, enamel eroded with RC showed more irregular interface than the LC-eroded surface. For eroded/ abraded enamel specimens, the hybrid layer was more evident than for only eroded enamel, except for ZC, which was similar to the control group. We suggest that the toothbrushing abrasion partially removed the fragile enamel layer, especially in the case of RC, allowing better hybrid layer formation, even though the bond strength remained as low as that for only the eroded enamel.

Practitioners should be aware when they restore enamel erosion lesions of patients with resin-based materials, as this property seems to be somehow negatively affected. However, once more it is important to state that this investigated potential did not consider the influence of saliva and its components present in the oral environment, which could alter the results $2,7,16$.

Clinical investigations have shown some concern about eroded-tooth restoration; however, most of them regard the adhesion failures in dentinn 23,24 . In the present study, we focused on early treatment strategies for dental erosion which has not reached dentin. Clinically, the findings of the present study are relevant for restoring enamel erosive lesions in a facial surface of anterior teeth, which in turn might compromise the aesthetic ${ }^{5}$. The early adhesive restoration could also prevent the progression of enamel erosion in anterior teeth. Thus, the results of the present study highlight the bonding mechanism when enamel is involved in early stages of erosive demineralization. Furthermore, the study also showed the importance of combining different analyses to better understand the adhesion process in enamel.

\section{CONCLUSIONS}

Based on the results of this study, we can conclude that all Coke drinks reduced the bond strength no matter the type. Qualitative aspects provided more detailed information, showing different failure mode and tag formation according to the type of Coke drink. Further investigation is required to evaluate the impact of the type of Coke drink on the adhesion to enamel and also to dentin over time, using higher erosive challenges and different bonding systems.

\section{ACKNOWLEDGMENTS}

This study was supported in part by grants given by the São Paulo Research Foundation (FAPESP), Process no. 2009/14986-0, and the National Council for Scientific and Technological Development (CNPq), Process no. 480038/2007-4. In Addition, this study was performed by V.D.M. and A.C.H. as fulfillment of their graduation research, which was supported by FAPESP (Processes no. 2009/01376-9 and 2009/01377-5, respectively). The authors are also grateful to Oral B and SDI, which donated the materials used in the study.

\section{REFERENCES}

1- Abdalla AI, El Zohairy AA, Abdel Mohsen MM, Feilzer AJ. Bond efficacy and interface morphology of self-etching adhesives to ground enamel. J Adhes Dent. 2010;12:19-25.

2- Bavbek AB, Dogan OM, Yilmaz T, Dogan A. The role of saliva in dental erosion and a prosthetic approach to treatment: a case report. J Contemp Dent Pract. 2009;10:74-80.

3- Correr GM, Alonso RC, Correa MA, Campos EA, Baratto-Filho F, Puppin-Rontani RM. Influence of diet and salivary characteristics on the prevalence of dental erosion among 12-year-old schoolchildren. J Dent Child. 2009;76:181-7.

4- D'Alpino PH, Pereira JC, Svizero NR, Rueggeberg FA, Pashley $\mathrm{DH}$. Factors affecting use of fluorescent agents in identification of resin-based polymers. J Adhes Dent. 2006;8:285-92.

5- Ehlen LA, Marshall TA, Qian F, Wefel JS, Warren JJ. Acidic beverages increase the risk of in vitro tooth erosion. Nut Res. 2008;28:299-303.

6- Federlin M, Thonemann B, Schmalz G, Urlinger T. Clinical evaluation of different adhesive systems for restoring teeth with erosion lesions. Clin Oral Investig. 1999;2:58-66.

7- Hara AT, González-Cabezas C, Creeth J, Zero DT. The effect of human saliva substitutes in an erosion-abrasion cycling model. Eur J Oral Sci. 2008;116:552-6. 
8- Jensdottir T, Arnadottir IB, Thorsdottir I, Bardow A, Gudmundsson K, Theodors A, et al. Relationship between dental erosion, soft drink consumption, and gastroesophageal reflux among Icelanders. Clin Oral Investig. 2004;8:91-6.

9- Magalhães AC, Wiegand A, Rios D, Honório HM, Buzalaf MA. Insights into preventive measures for dental erosion. J Appl Oral Sci. 2009;17:75-86.

10- Marshall SJ, Bayne SC, Baier R, Tomsia AP, Marshall GW. A review of adhesion science. Dent Mater. 2010;26:11-6.

11- Moron BM, Miyazaki SS, Ito N, Wiegand A, Vilhena F, Buzalaf $M A$, et al. Impact of different fluoride concentrations and $\mathrm{pH}$ of dentifrices on tooth erosion/abrasion in vitro. Aust Dent $\mathrm{J}$. 2013;58:106-11.

12- Mulic A, Tveit AB, Hove LH, Skaare AB. Dental erosive wear among Norwegian wine tasters. Acta Odontol Scand. 2011;69(1):21-6.

13- Pashley DH, Tay FR, Breschi L, Tjäderhane L, Carvalho RM, Carrilho $M$, et al. State of the art etch-and-rinse adhesives. Dent Mater. 2011;27:1-16.

14- Perdigão J. Dentin bonding-variables related to the clinical situation and the substrate treatment. Dent Mater. 2010;26:e2437.

15- Perdigão J, Dutra-Corrêa M, Saraceni S, Ciaramicoli M, Kiyan V, Queiroz CS. Randomized clinical trial of four adhesion strategies: 18-month results. Oper Dent. 2012;37:3-11.

16- Piangprach T, Hengtrakool C, Kukiattrakoon B, KedjaruneLeggat $U$. The effect of salivary factors on dental erosion in various age groups and tooth surfaces. J Am Dent Assoc. 2009;140:113743.

17- Reis A, Higashi C, Loguercio AD. Re-anatomization of anterior eroded teeth by stratification with direct composite resin. J Esthet Restor Dent. 2009;21:304-16.
18- Rios D, Honório HM, Magalhães AC, Buzalaf MA, Palma-Dibb $R G$, Machado $M A$, et al. Influence of toothbrushing on enamel softening and abrasive wear of eroded bovine enamel: an in situ study. Braz Oral Res. 2006;20:148-54.

19- Rios D, Honório HM, Magalhães AC, Wiegand A, Andrade Moreira Machado MA, Buzalaf MA. Light cola drink is less erosive than the regular one: an in situ/ex vivo study. J Dent. 2009;37:163-6.

20- Rios D, Santos FC, Honório HM, Magalhães AC, Wang L, Andrade Moreira Machado MA, et al. An in situ/ex vivo comparison of the ability of regular and light colas to induce enamel wear when erosion is combined with abrasion. Quintessence Int. 2011;42:44-50.

21- Schlueter N, Peutzfeldt A, Ganss C, Lussi A. Does tin pretreatment enhance the bond strength of adhesive systems to enamel? J Dent. 2013;41:642-52.

22- Serra MC, Messias DC, Turssi CP. Control of erosive tooth wear: possibilities and rationale. Braz Oral Res. 2009;23:49-55. 23- Spreafico RC. Composite resin rehabilitation of eroded dentition in a bulimic patient: a case report. Eur J Esthet Dent. 2010;5:28-48.

24- Wilder AD Jr, Swift EJ Jr, Heymann HO, Ritter AV, Sturdevant JR, Bayne SC. A 12-year clinical evaluation of a three-step dentin adhesive in noncarious cervical lesions. J Am Dent Assoc. 2009; 140:526-35.

25- Yu H, Wegehaupt FJ, Wiegand A, Roos M, Attin T, Buchalla W. Erosion and abrasion of tooth-colored restorative materials and human enamel. J Dent. 2009;37:913-22.

\section{ERRATUM}

http:/dx.doi.org/10.1590/1678-77572014er001

Due to a publishing error the article "Erosive cola-based drinks affect the bonding to enamel surface: an in vitro study", published at Journal of Applied Oral Science 22(5):434-441 was printed with the following errors:

Page 434 - In abstract: Material and Methods: "Forty-six bovine enamel specimens..." should be read "Fifty-six bovine enamel specimens...".

Page 435 - Figure 1

\begin{tabular}{l|l} 
Light Coke & “...tritability=12 mL (0. N NaOH).” \\
\hline should be read \\
\hline Light Coke & “...tritability=12 mL (0.1 N NaOH).”
\end{tabular}

